\title{
POLA MUSIM PENANGKAPAN IKAN LAYUR (Trichiurus spP) DI PERAIRAN TELUK PALABUHANRATU, SUKABUMI, JAWA BARAT
}

\author{
Fishing season pattern of hairtail fish (Trichiurus spp) in Palabuhanratu Bay waters, Sukabumi, West \\ Java \\ Oleh: \\ Widuri Putri Branenda ${ }^{1}$, Zulkarnain ${ }^{1}$, Retno Muninggar ${ }^{1}$, Fis Purwangka ${ }^{1}$, Izza \\ Mahdiana Apriliani ${ }^{2}$ \\ ${ }^{1}$ Departemen Pemanfaatan Sumberdaya Perikanan, FPIK, IPB \\ ${ }^{2}$ Fakultas Perikanan dan Ilmu Kelautan, Universitas Padjadjaran \\ Korespondensi: zulkarnain@apps.ipb.ac.id
}

\begin{abstract}
ABSTRAK
Kegiatan penangkapan ikan layur di perairan Teluk Palabuhanratu umumnya menggunakan pancing layur dan ikan layur merupakan salah satu komoditas ekspor penting dan dominan tertangkap. Salah satu faktor yang mendukung keberhasilan penangkapan yaitu pengetahuan mengenai musim penangkapan ikan layur. Tujuan penelitian ini adalah mengetahui pola musim penangkapan ikan layur, hubungan panjang dan berat ikan layur, mengetahui Catch Per Unit Effort (CPUE) ikan layur, dan hubungan panjang total dengan panjang mulut dan lebar bukaan mulut ikan layur. Penelitian ini menggunakan metode penelitian deskriptif dengan jenis penelitian studi kasus. Metode analisis data yang digunakan adalah metode rata-rata bergerak, metode hubungan panjang dan berat, analisis CPUE dan analisis regresi linear. Hasil penelitian menunjukkan bahwa berdasarkan indeks musim penangkapan diketahui pola musim ikan layur terdapat pada bulan Desember, Februari, Maret, April, Oktober dan November. Hubungan panjang dan berat ikan layur bersifat alometrik negatif yang berarti pola pertumbuhan panjang ikan layur lebih cepat daripada pertumbuhan beratnya. Hubungan CPUE dengan effort merupakan hubungan yang positif dengan $y=0,0016 x+12,337$. Pertambahan panjang ikan layur akan mempengaruhi panjang mulut dan lebar bukaan mulut ikan layur.
\end{abstract}

Kata kunci: CPUE, musim penangkapan, Palabuhanratu, pancing layur

\begin{abstract}
Hairtail fisheries in Palabuhanratu Bay waters generally used handline and the hairtail fish is one of important commodity as exportable and dominant catch in Palabuhanratu bay waters. One of the supporting factors in the hairtail fishing is the fishing season's knowledge. Objectives of this research are to understanding about the hairtail fishing season; relation of fish length and weight; catch per unit effort (CPUE), and relations of total length with mouth length and wide opened mouth of hairtail fish. This research was used descriptive methods with case study. Data analysis was used moving average, fish length and weight relations methods, CPUE and linear regression analysis. The results of this research showed the fishing season occured in December, February, March, April, October and November. The fish length and weight relations are significant negative allometric, it means the growth fish length faster than the fish weight. The relations of CPUE and effort was a positive with $y=0,0016 x+12,337$. The growth fish length was influence to mouth length and wide opened mouth of hairtail fish.
\end{abstract}

Key words: CPUE, fishing season, handline, Palabuhanratu 


\section{PENDAHULUAN}

Palabuhanratu memiliki Pelabuhan Perikanan Nusantara yang melayani pendaratan kapal hingga ukuran kapal 90 GT. Berbagai komoditi ikan didaratkan ada pelabuhan tersebut. Komoditi ikan yang paling dominan adalah ikan jenis tuna (Thunnus sp) dan layur (Trichiurus sp) dan keduanya merupakan komoditas ekspor andalan dari Palabuhanratu. Ikan layur mempunyai bentuk tubuh yang pipih, panjang, mulut yang lebar dengan warna putih keperakan dan mengkilat, sehingga mudah untuk dibedakan dari jenis ikan lainnya (Badrudin dan Wudianto. 2004). Permintaan ikan layur cenderung meningkat terutama pada musim ikan. Permintaan ekspor mencapai 100-500 ton/bulan dengan kondisi ini menyebabkan peluang yang cukup besar di pasaran internasional (Anita 2003).

Penelitian mengenai pola musim penangkapan ikan layur di Palabuhanratu sangat penting dikarenakan dapat memberikan informasi mengenai waktu penangkapan ikan layur yang tepat, sehingga mempermudah nelayan dalam melakukan penangkapan ikan secara efektif dan efisien. Hal tersebut dapat meningkatkan pendapatan nelayan secara optimal.

Menurut Fauzi dan Anna (1989), alat tangkap yang dominan digunakan untuk menangkap ikan layur di Palabuhanratu adalah pancing ulur. Hal ini dikarenakan ikan layur lebih banyak tertangkap dengan alat tersebut, selain itu struktur alat pancing yang tidak rumit membuat nelayan mudah dalam penggunaannya. Pancing ulur tidak dapat menangkap ikan layur dalam jumlah yang banyak dalam waktu yang singkat, sehingga pancing ulur dapat digunakan untuk mewujudkan perikanan layur yang berkelanjutan dengan alat tangkap yang ramah lingkungan.

Permasalahan yang diangkat dalam penelitian ini adalah mengetahui waktu penangkapan ikan layur yang tepat sehingga memberikan keuntungan yang optimal bagi para nelayan. Selain itu, mengetahui beberapa hal mengenai ukuran ikan layur yang diperbolehkan untuk ditangkap agar potensi sumberdaya ikan layur tetap lestari dan berkelanjutan, menghitung Catch Per Unit Effort (CPUE), mengetahui adanya pengaruh antara panjang total ikan layur dengan panjang mulut dan lebar bukaan mulut ikan layur, sehingga dapat membantu nelayan dalam memilih ukuran mata pancing yang akan digunakan.

Tujuan dalam penelitian ini adalah untuk menganalisis pola musim penangkapan ikan layur, menganalisis hubungan panjang dan berat ikan layur, menganalisis Catch Per Unit Effort (CPUE) ikan layur yang didaratkan di PPN Palabuhanratu, Sukabumi, dan menganalisis tertangkapnya ikan layur berdasarkan perbandingan antara panjang mulut ikan dan lebar bukaan mulut ikan dengan ukuran umpan serta mata pancing.

\section{METODE PENELITIAN}

Penelitian ini telah dilaksanakan pada bulan Februari-April 2016 di PPN Palabuhanratu, Sukabumi, Jawa Barat. Alat dan bahan penelitian yang digunakan berupa baki, penggaris dengan ketelitian 0,1 cm untuk mengukur panjang ikan, neraca digital dengan ketelitian 0,001 gram untuk menimbang berat ikan, meteran untuk mengukur dimensi pancing ulur dan ikan layur sebagai sampel ikan. Data yang dikumpulkan meliputi data primer dan data sekunder. Data primer terdiri dari panjang total ikan layur, lebar bukaan mulut, panjang mulut dan berat ikan layur yang dilakukan secara langsung setelah bongkar ikan dari palkah ikan di lapangan, serta melakukan pengamatan dengan mengikuti kegiatan operasi penangkapan ikan layur dan melakukan wawancara dengan nelayan. Data sekunder yang dikumpulkan adalah data berkala (time series data) hasil tangkapan, upaya penangkapan dalam kurun waktu enam tahun terakhir (2010-2015). Data sekunder tersebut berupa data hasil tangkapan/bulan dan upaya penangkapan ikan unit/bulan yang diperoleh dari Balai Pusat Statistik PPN Palabuhanratu. 


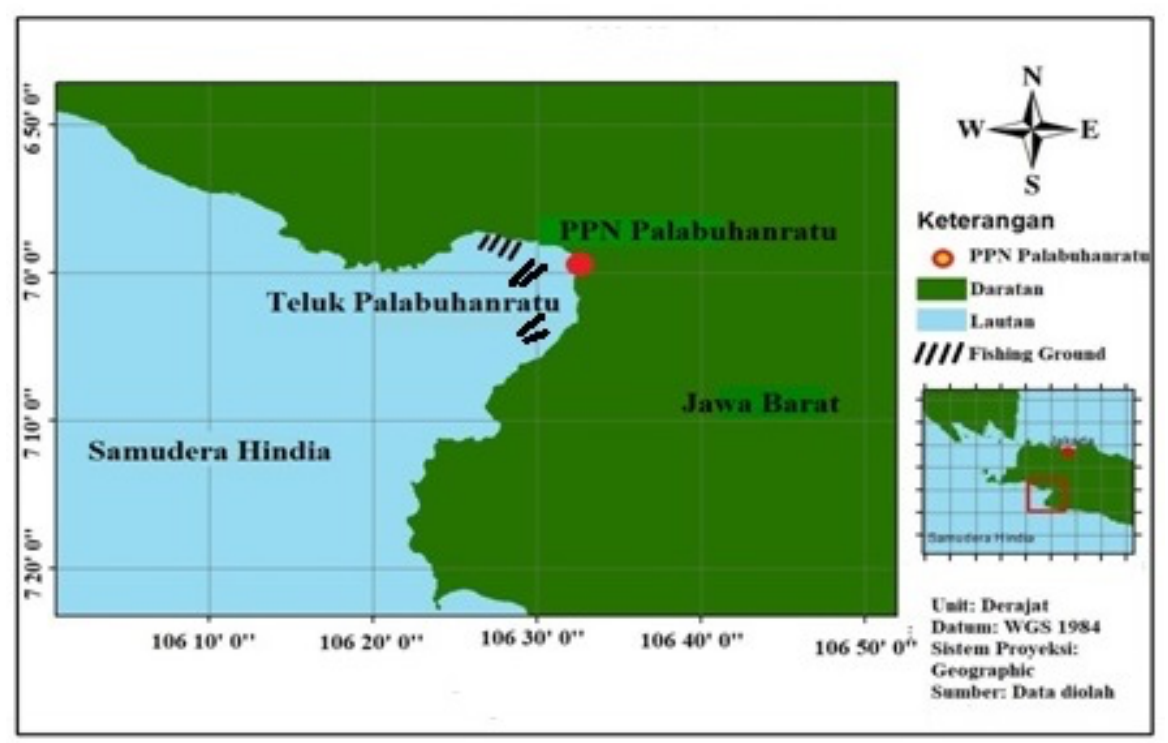

Gambar 1 Peta lokasi Pelabuhan Perikanan Nusantara (PPN) Palabuhanratu
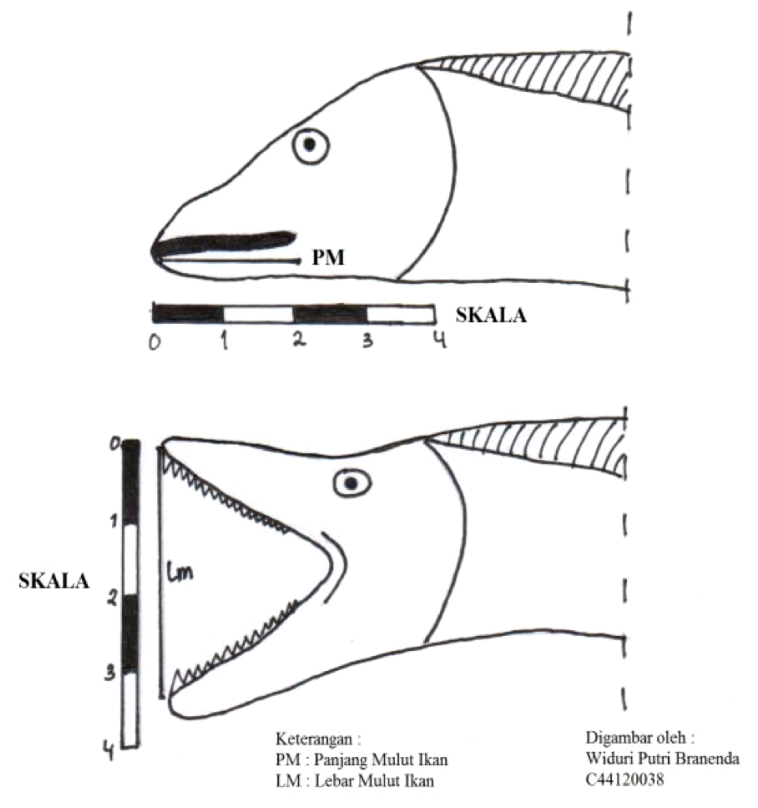

Gambar 2 Pengukuran panjang mulut dan lebar bukaan mulut ikan layur

Metode penelitian dilakukan menggunakan metode deskriptif yang merupakan metode yang menggambarkan dan menjelaskan adanya dari suatu variabel, gejala dan keadaan berdasarkan yang tampak. Metode deskriptif ini bertujuan untuk menggambarkan sifat atau keadaan umum tentang perikanan layur di PPN Palabuhanratu.

Analisis data yang digunakan untuk mengetahui pola musim ikan layur adalah analisis deskriptif dengan data berkala (time series data) hasil tangkapan, upaya penangkapan selama periode 2010-2015. Pola musim penangkapan ikan layur dihitung dengan menggunakan analisis deret waktu terhadap hasil tangkapan.

Pola musim penangkapan ikan layur dapat dihitung dengan menggunakan analisis deret waktu terhadap hasil tangkapan menurut Dajan (1998), telah menyusun langkah-langkah sebagai berikut: menyusun deret CPUE dalam periode kurun waktu 6 tahun, yaitu CPUEi $=\mathrm{Ni}$, dimana $\mathrm{Ni}=\mathrm{CPUE}$ 
urutan ke-i, dan $i=1,2,3, \ldots$, ; menyusun rata-rata bergerak CPUE selama 12 bulan $(\mathrm{RG})$ yaitu $\mathrm{RGi}=[1$ $(1+5$ CPUEi $)] /[12 \mathrm{i}=\mathrm{i}-6]$, dimana $\mathrm{RGi}$ = rata-rata bergerak 12 bulan urutan ke-I, CPUEi = CPUE urutan ke-I, $I=7,8, \ldots, n-5$; menyusun rata-rata bergerak CPUE terpusat (RGP), yaitu $R G P i=1 / 2 \sum i=1[R G i]$, dimana $\mathrm{RGPi}$ = rata-rata bergerak terpusat ke-I, RG = rata-rata bergerak 12 bulan urutan ke-I, $\mathrm{I}=$ $7,8, \ldots, \mathrm{n}-5$; menghitung rasio rata-rata tiap bulan $(\mathrm{Rb})$ yaitu $\mathrm{Rbi}=[\mathrm{CPUE}] /[\mathrm{RGPi}]$, dimana $\mathrm{I}=$ bulan ke $1,2, \ldots ., 12$; menyusun nilai rata-rata dalam suatu matrik berukuran $\mathrm{i} x \mathrm{j}$ yang disusun untuk setiap bulan. Selanjutnya menghitung nilai total rasio rata-rata tiap bulan, kemudian menghitung total rasio ratarata secara keseluruhan dan pola musim penangkapan, yaitu : rasio rata-rata untuk bulan ke-i (RBBi), yaitu $\mathrm{RBBi}=1 / \mathrm{n}$ [Rbij]; jumlah rasio rata-rata bulanan (JRBB), yaitu $\Sigma \mathrm{i}=1=\mathrm{RBBi}$; Indeks Musim Penangkapan ikan (IMP), yaitu FK = [1200]/[JRBB], dan IMP = RBBi x FK, dimana FK = faktor koreksi, $\mathrm{RBBi}=$ rata-rata dari Rbij untuk bulan $\mathrm{ke}-\mathrm{I}, \mathrm{Rbij}$ = rasio rata-rata bulanan dalam matriks ukuran $\mathrm{i} x \mathrm{j}, \mathrm{I}$ $=1,2, \ldots, 12$, dan $\mathrm{J}=1,2,3, \ldots, \mathrm{n}$.

Analisis pertumbuhan ikan layur dilihat dari hubungan panjang dan berat (Effendie 1979) dengan menggunakan rumus umum adalah $\mathrm{W}=\mathrm{aL}{ }^{\mathrm{b}}$, dimana a dan $\mathrm{b}$ adalah konstanta yang didapatkan dari perhitungan regresi, sedangkan $\mathrm{W}$ adalah berat total dan $\mathrm{L}$ adalah panjang total. Logaritma persamaan tersebut menjadi: $\mathrm{W}=\log \mathrm{a}+\mathrm{b} \log \mathrm{L}$ atau $\mathrm{y}=\mathrm{a}+\mathrm{bx}$. Analisis panjang dan berat ikan ini dilakukan menggunakan Microsoft Excel. Nilai $b$ diuji terhadap nilai $b=3$ atau $b \neq 3$ menggunakan ujit dengan tingkat kepercayaan 95\%. Hipotesis uji-t pada statistik yaitu: $\mathrm{H}_{0}: \mathrm{b}=3$, hubungan panjang dengan berat adalah isometrik. $\mathrm{H}_{1}: \mathrm{b} \neq 3$, hubungan panjang dengan berat adalah alometrik, dimana: alometrik positif, jika $b>3$ (pertambahan berat lebih cepat daripada pertambahan panjang) dan, alometrik negatif, jika $b<3$ (pertambahan panjang lebih cepat daripada pertambahan berat). Dasar pengambilan keputusan: $\mathrm{T}_{\text {hit }}>\mathrm{T}_{\mathrm{tab}}$; maka $\mathrm{H}_{0}$ ditolak. : $\mathrm{T}_{\text {hit }}<\mathrm{T}_{\mathrm{tab}} ;$ maka $\mathrm{H}_{0}$ diterima.

Analisis distribusi frekuensi panjang berat ikan layur digunakan untuk menganalisis panjang dan berat ikan layur yang dilakukan selama kegiatan penelitian. Adapun cara dalam menentukan daftar distribusi frekuensi (Walpole 1995) adalah sebagai berikut: Menentukan rentang, yaitu Rentang = nilai maksimum - nilai minimum; banyak kelas interval, yaitu $K=1+3,3 \log n$, dimana $K=$ jumlah kelas interval, $\mathrm{N}=$ jumlah data observasi, Log =logaritma; panjang kelas interval, yaitu $\mathrm{P}=\mathrm{Rentang} /$ Banyak kelas interval.

Analisis CPUE adalah menghitung nilai hasil tangkapan per upaya penangkapan berdasarkan data hasil upaya penangkapan ikan layur. Tujuan dari penghitungan CPUE adalah untuk mengetahui kelimpahan ikan layur yang didasari oleh pembagian total hasil tangkapan (catch) dengan upaya penangkapan (effort). Rumus yang digunakan untuk menghitung nilai CPUE adalah (Gulland JA 1983) : CPUEi $=$ [Catch i]/[Effort i], dimana CPUEi = hasil tangkapan per upaya penangkapan layur pada tahun kei (kg per trip), catch $i=$ hasil tangkapan layur pada tahun ke-i $(\mathrm{kg})$, effort $i=$ upaya penangkapan layur pada tahun ke-i (trip), $\mathrm{i}=1,2, . . \mathrm{n}$.

Analisis regresi linear digunakan untuk membandingkan panjang dengan panjang mulut ikan layur serta panjang total dengan lebar bukaan mulut ikan layur. Persamaan regresi linear sederhana yaitu $\mathrm{Y}=\mathrm{a}+\mathrm{b}(\mathrm{x})$, dimana $\mathrm{a}=$ konstanta, $\mathrm{b}=$ koefisien regresi, $\mathrm{X}=$ variabel independen (variabel bebas), $\mathrm{Y}=$ variabel dependen (variabel tak bebas).

Analisis batas ukuran mata pancing dan umpan pada alat tangkap pancing ulur digunakan untuk mengetahui batas ukuran mata pancing dan umpan tertangkapnya ikan layur, yaitu $\mathrm{X}=\mathrm{a}+\mathrm{b}(\mathrm{cm})$, dimana $\mathrm{a}=$ setengah tinggi mata pancing (umpan no 8, 9, dan 10), $\mathrm{b}=$ tinggi umpan, $\mathrm{X}$ = setengah tinggi mata pancing ditambah tinggi umpan. Dasar pengambilan keputusan: Jika PM > X ; maka ikan tertangkap. Jika LM > Y ; maka ikan tertangkap. 

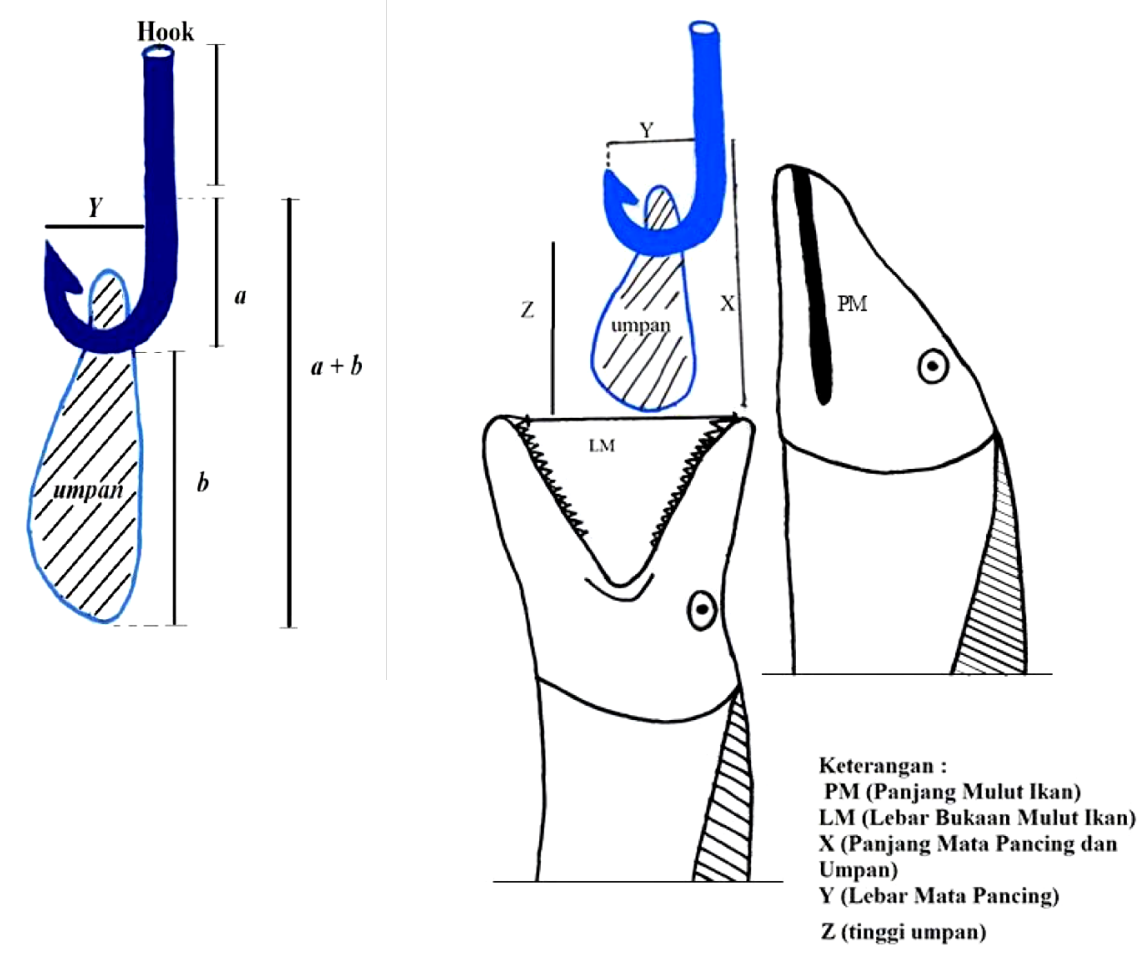

Gambar 3 Pengukuran panjang mulut dan lebar bukaan mulut ikan layur terhadap ukuran mata pancing dan umpan

\section{HASIL DAN PEMBAHASAN}

Produksi ikan layur mengalami fluktuatif yang disebabkan oleh beberapa faktor seperti faktor internal dan faktor eksternal. Faktor internal yang berpengaruh yaitu, jumlah nelayan, jumlah alat tangkap, trip penangkapan ikan serta jenis dan ukuran alat tangkap. Faktor eksternal yang mempengaruhi volume produksi antara lain, cuaca, musim, kondisi perikanan laut dan sebagainya. Produksi ikan layur yang terdapat di PPN Palabuhanratu dengan alat tangkap pancing ulur selama tahun 2010 sampai dengan 2015 disajikan pada Gambar 4.

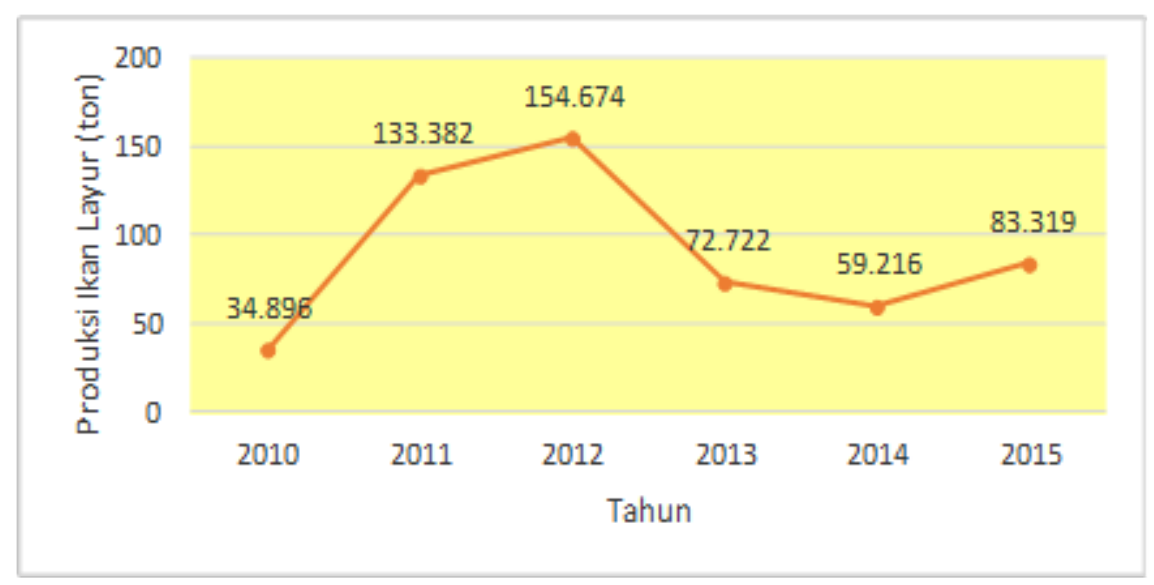

Gambar 4 Produksi tahunan ikan layur dengan alat tangkap pancing ulur di PPN Palabuhanratu

Berdasarkan Gambar di atas, terjadinya fluktuasi hasil tangkapan dengan kecenderungan meningkat dari tahun 2010 sampai 2012. Namun terjadi penurunan sampai dengan tahun 2014 dan 
kembali meningkat sampai tahun 2015. Rata-rata produksi ikan layur yang ditangkap dengan pancing ulur di PPN Palabuhanratu selama 6 tahun terakhir mencapai 89,7 ton per tahun nya.

Analisis indeks musim penangkapan ikan layur menggunakan data CPUE bulanan dalam kurun waktu tertentu (minimal 5 tahun). Berdasarkan nilai IMP maka akan diketahui kecenderungan musim penangkapan ikan layur sehingga dapat ditentukan waktu penangkapan yang tepat. Nilai indeks musim penangkapan (IMP) ikan layur di PPN Palabuhanratu kurun waktu 2010-2015 dapat dilihat pada Tabel 1.

Berdasarkan nilai IMP rata-rata yang didapatkan, maka kecenderungan pola musim penangkapan ikan layur menunjukkan bahwa pada bulan Februari, Maret, April, Oktober, November dan Desember merupakan musim penangkapan ikan layur (waktu yang tepat untuk menangkap ikan layur). Pada bulan tersebut merupakan bulan pada musim barat dan musim peralihan. Adapun pada bulan Juni, Juli, Agustus, dan September yang merupakan musim timur, kurang efektif untuk dilakukan operasi penangkapan ikan layur dikarenakan pada bulan tersebut, ikan layur berjumlah sedikit. Kecenderungan stabil berdasarkan nilai IMP terlihat jelas pada bulan Mei-September (kurang efektif untuk operasi penangkapan ikan layur) dan bulan Oktober-Desember, Februari-April (efektif untuk operasi penangkapan ikan layur). Namun, terjadi fluktuasi dengan tren menurun saat bulan Januari yang menunjukkan kurang efektif nya untuk dilakukan operasi penangkapan.

Tabel 1 Indeks Musim Penangkapan (IMP) ikan layur di PPN Palabuhanratu

\begin{tabular}{lcl}
\hline Bulan & Nilai IMP (\%) & Musim di Indonesia \\
\hline Januari & 97 & Musim Barat \\
Februari & 101 & Musim Barat \\
Maret & 161 & Musim Barat \\
April & 129 & Musim Peralihan \\
Mei & 82 & Musim Peralihan \\
Juni & 66 & Musim Timur \\
Juli & 75 & Musim Timur \\
Agustus & 47 & Musim Timur \\
September & 48 & Musim Timur \\
Oktober & 127 & Musim Peralihan \\
November & 130 & Musim Peralihan \\
Desember & 137 & Musim Barat \\
\hline Rata-rata tahunan & 100 & \\
Rata-rata musim timur & 59 & Dibawah rata-rata \\
Rata-rata musim barat & 124 & Diatas rata-rata \\
Rata-rata musim peralihan & 117 & Diatas rata-rata \\
\hline
\end{tabular}

Harjanti et al. (2012), pola musim penangkapan ikan layur berdasarkan IMP terjadi bulan Agustus, November-Januari, dan April-Mei, serta puncak musim penangkapan ikan layur terjadi pada bulan April yang merupakan musim peralihan.

Menurut Sari (2008), tingkat kepenuhan lambung terbesar pada ikan layur jenis Trichiurus savala terjadi di bulan November. Indeks isi lambung merupakan indikasi untuk menentukan aktivitas makan ikan per waktu penangkapan, hal ini sebanding dengan tingkat IMP yang tinggi berdasarkan Tabel 1 dibulan November sebesar 130\%.

Berdasarkan penelitian yang telah dilakukan, membuktikan bahwa adanya pola musim yang cenderung berubah setiap tahunnya, namun pola musim tersebut lebih banyak terjadi pada bulan November, Desember dan April. Pola musim penangkapan tersebut dapat digunakan untuk membantu 
nelayan layur dalam mengetahui waktu penangkapan yang tepat sehingga penangkapan bisa dilakukan secara efektif dan efisien.

Musim barat, peralihan dan timur memiliki hubungan yang saling berkaitan berdasarkan nilai rataan \pm standard error. Nilai rataan \pm standard error pada musim barat sebesar 17,626; musim peralihan 13,491; dan musim timur 7,958 yang ditunjukan pada Gambar 5. Pada musim barat dan peralihan terlihat jelas hubungan yang tidak berbeda nyata sama halnya pada musim peralihan dan musim timur yang tidak berbeda nyata. Namun, musim barat dan musim timur terlihat hubungan yang berbeda nyata.

Ikan yang tertangkap oleh nelayan memiliki ukuran panjang dan berat yang sangat beragam. Namun, tidak semua ikan layur dapat ditangkap dengan ukuran yang berbeda, karena ikan layur memiliki fase pemijahan. Menurut Widyanto (2008) pada bulan yang merupakan musim peralihan, tidak seharusnya dilakukan penangkapan karena dibulan tersebut ikan layur sedang memijah. Akan tetapi, para nelayan tetap melakukan penangkapan ikan karena dianggap sangat menguntungkan.

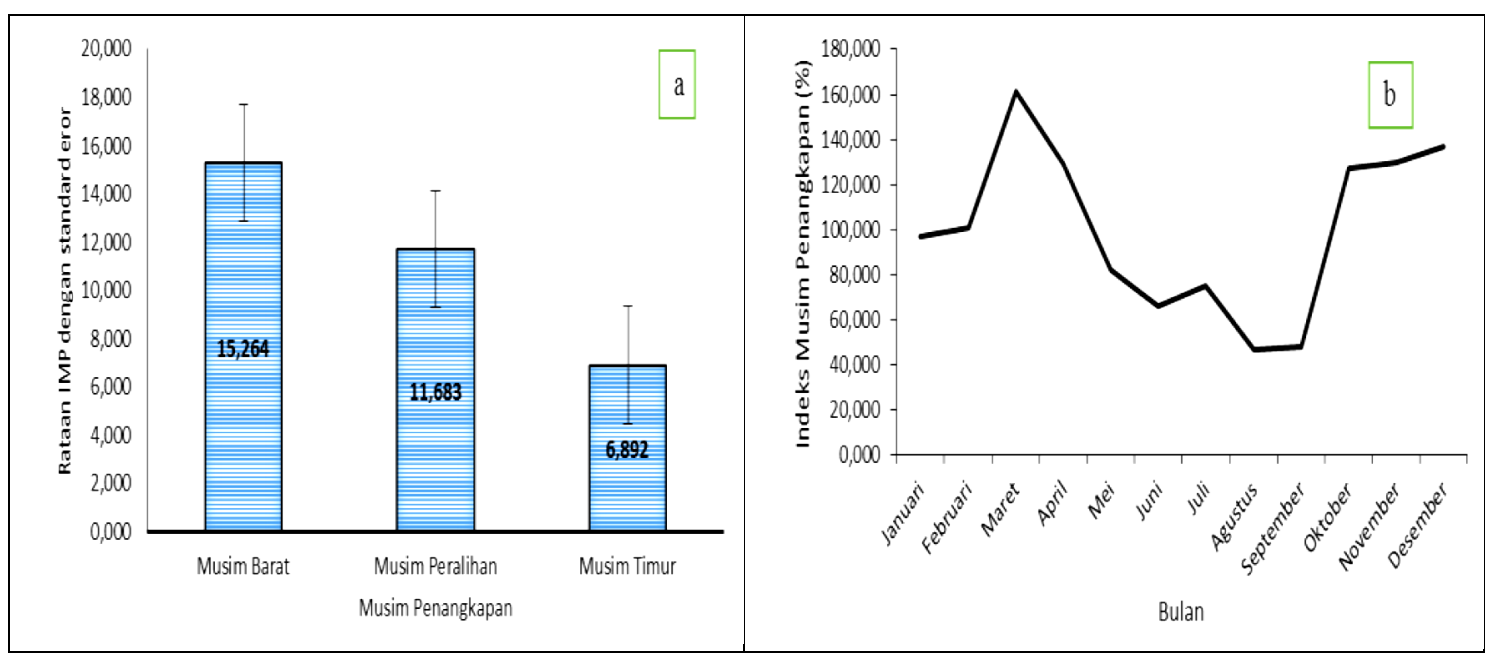

Gambar 5 Rataan nilai IMP \pm standard error (a) dan IMP Perbulan (b)

Length of Maturity ( $\mathrm{Lm}$ ) ikan layur sepanjang 46,3 cm (Fishbase.org) yang jumlah ikan layak tangkap nya lebih besar dibandingkan dengan dengan tidak layak tangkap. Begitupula dengan berat layak tangkap $\mathrm{W}=470,7$ gram hasil ikan layak tangkapnya lebih besar dibandingkan dengan ikan tidak layak tangkap. Selang kelas panjang ikan layur dan selang kelas berat ikan layur selama penelitian disajikan pada Gambar 6 dan 7.

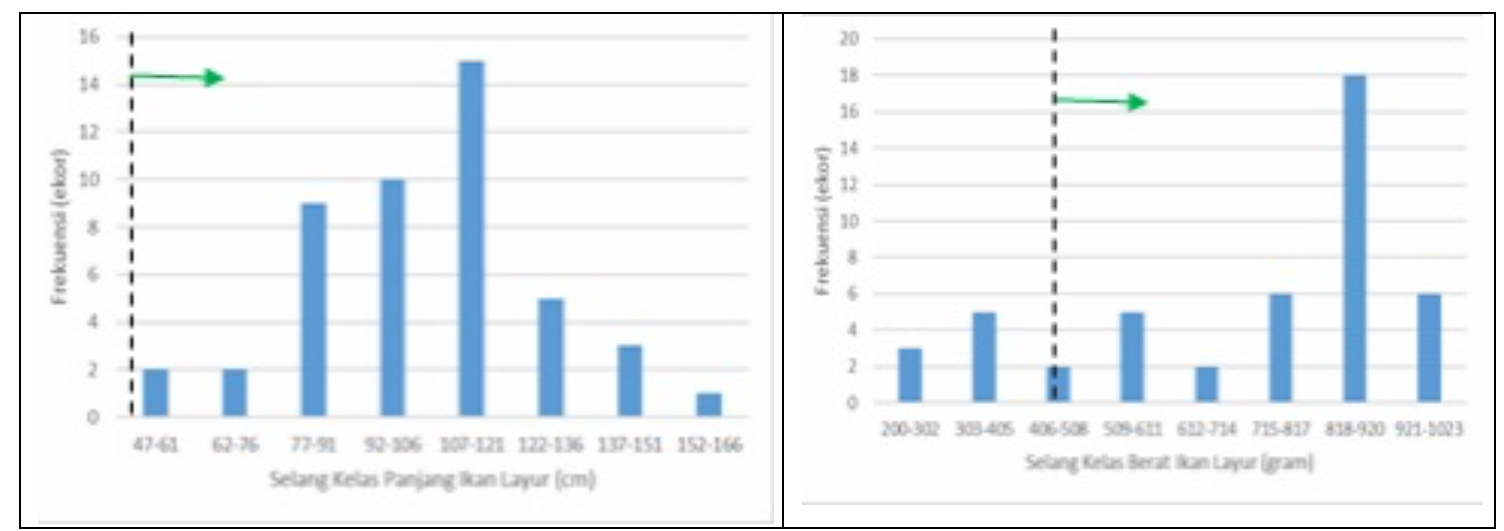

Gambar 6 Selang panjang ikan layur

Gambar 7 Selang berat ikan layur

Berdasarkan panjang total dan berat ikan layur yang didapatkan selama penelitian, ukuran ikan layur yang banyak tertangkap nelayan berkisar 81-97 cm dengan bobot ikan berkisar 884-997 gr. 
Hubungan panjang berat dapat dilihat pada Gambar 8. Berdasarkan Gambar 8 diperoleh model hubungan panjang dengan berat ikan layur menggunakan uji-t dengan persamaan hubungan panjang dan berat ikan layur yaitu $\mathrm{W}=0,3136 \mathrm{~L} 1,6667$ dengan nilai koefisien determinasi (R2) 0,7776 yang artinya didapatkan nilai a sebesar 0,3136 dan nilai b sebesar 1,6667. Analisis uji-t diperoleh $\mathrm{T}_{\text {hit }}>\mathrm{T}_{\text {tab }}$ yang menunjukkan pola pertumbuhan ikan layur bersifat alometrik negatif karena $b \neq 3$ dan nilai $b<3$ yang artinya pertambahan panjang lebih cepat daripada pertambahan beratnya. Berdasarkan penelitian Vianita (2014) pertumbuhan ikan layur bersifat alometrik negatif $(b<3)$ dengan nilai b sebesar 2,68 yang berarti pertambahan panjang lebih cepat daripada pertambahan beratnya sehingga ikan layur memiliki ukuran tubuh yang memanjang.

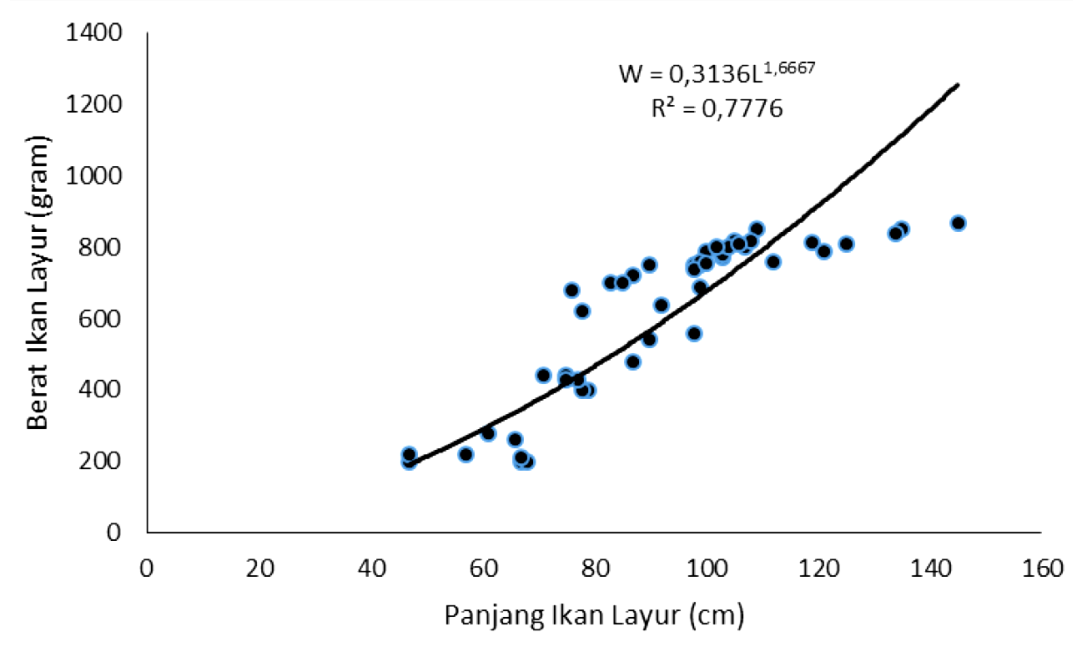

Gambar 8 Hubungan panjang dan berat ikan layur di PPN Palabuhanratu

Catch Per Unit Effort (CPUE) merupakan hubungan antara jumlah unit penangkapan (effort) dengan jumlah hasil tangkapan (produksi). CPUE yang dihitung didalam penelitian ini selama enam tahun (2010-2015), data mengenai produksi hasil tangkapan, jumlah trip, dan CPUE dapat dilihat pada Gambar 9.

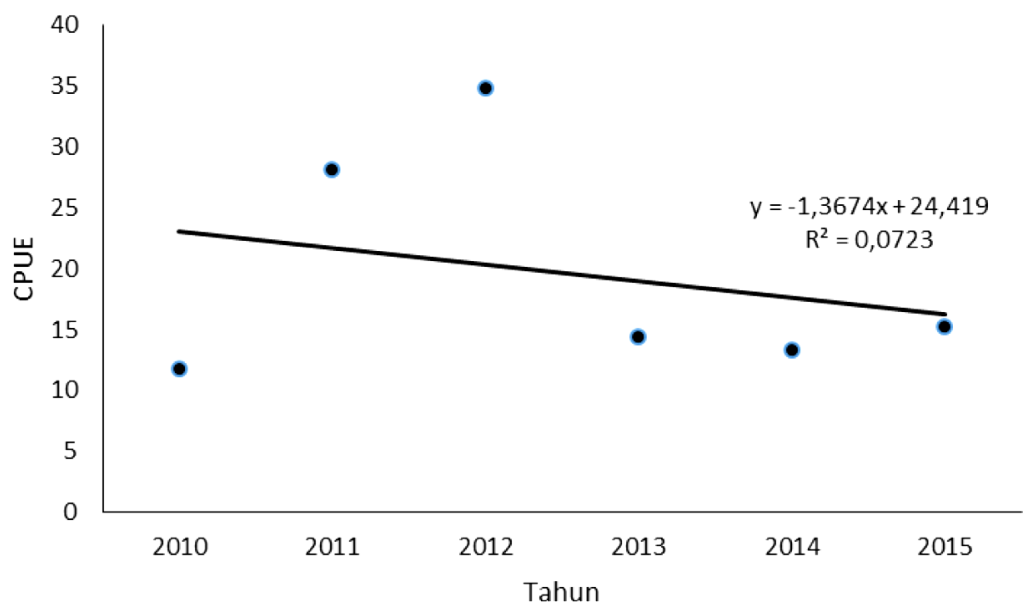

Gambar 9 CPUE pertahun selama 2010-2015 di PPN Palabuhanratu

Berdasarkan Gambar 9 tersebut dapat diketahui bahwa terjadi peningkatan hasil tangkapan (produksi) yang dikuti dengan peningkatan unit penangkapan (trip) selama tahun 2010-2012 sehingga CPUE pada tahun tersebut cenderung meningkat. Namun, terjadi penurunan CPUE secara drastis pada tahun 2013 hingga 41,1 \% yang disebabkan oleh peningkatan jumlah penangkapan (trip) namun hasil 
tangkapan (produksi) menurun. Pada tahun 2014 dan 2015 kembali tabil dengan peningkatan CPUE yang diikuti dengan peningkatan hasil tangkapan (produksi).

Hubungan antara CPUE dengan effort pada sumberdaya ikan layur didapatkan persamaan $\mathrm{y}=$ $0,0016 x+12,337$ dengan $R^{2}=0,0214$, bahwa semakin tinggi effort (trip) kecenderungan nilai CPUE semakin naik dengan tingkat kenaikan yang rendah (Gambar 10). Adapun hubungan CPUE per tahun nya didapatkan persamaan $\mathrm{y}=-1,3674 \mathrm{x}+24,419$ dengan $\mathrm{R}^{2}=0,0723$, bahwa nilai CPUE kecenderungannya semakin menurun setiap tahunnya dengan tingkat penurunan yang rendah. Pada Gambar 9 terjadi peningkatan produksi ikan layur pada tahun 2011-2012 yang drastis yang menyebabkan grafik hubungan CPUE dan effort cenderung naik dengan nilai $\mathrm{R}^{2}$ yang kecil. Hal tersebut menunjukkan bahwa sumberdaya ikan layur mengalami gejala overfishing dikarenakan fluktuasi produksi ikan layur yang cenderung menurun.

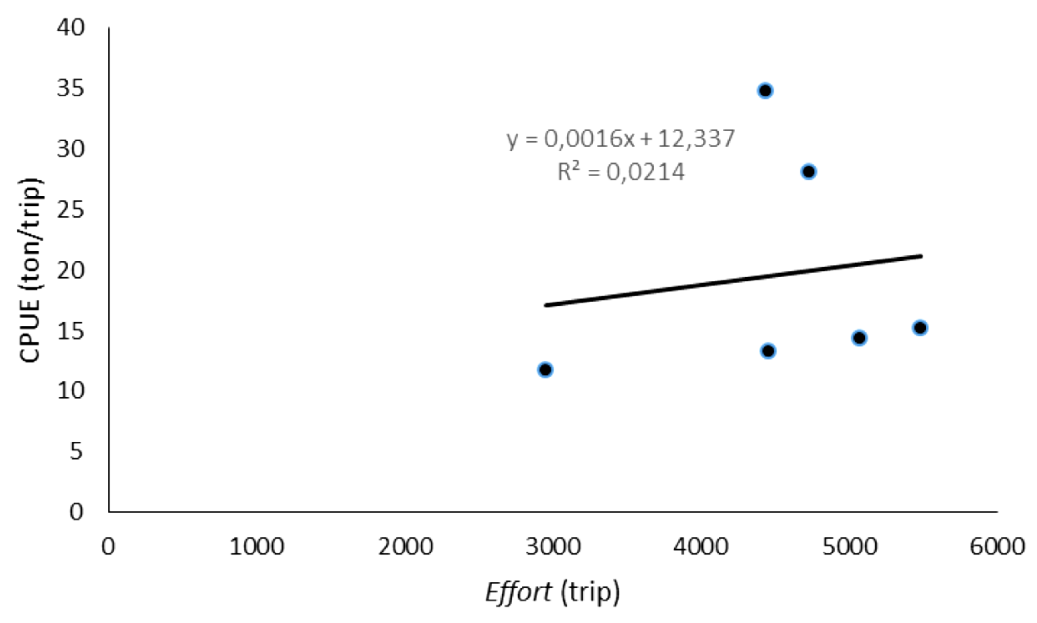

Gambar 10. Hubungan antara CPUE dengan effort

Berdasarkan penelitian Harjanti (2012) didapatkan persamaan hubungan CPUE dengan effort y $=0,0677-4 \cdot 10-6 \mathrm{X}$ dengan $\mathrm{R}^{2}=0,8247$ yang artinya setiap terjadi peningkatan effort sebanyak 1 trip maka CPUE akan berkurang sebesar 0,000004 ton per trip nya. Hubungan CPUE dengan effort negatif, sehingga menunjukkan kondisi sumberdaya ikan layur telah mengalami overfishing secara biologi (biological overfishing).

Sampel ikan layur yang diperoleh nelayan adalah hasil tangkapan nelayan pancing layur. Ikan tersebut tertangkap pada mata pancing nomor 8, 9, dan 10. Pada angka dengan nilai panjang mulut 3,5 $\mathrm{cm}$ masih dapat tertangkap dengan pancing ulur dikarenakan adanya kelenturan umpan ikan tembang sehingga dengan panjang minimum 3,5 cm untuk hook no. 8 ikan layur masih dapat tertangkap. Tertangkapnya ikan tersebut dianalisis dengan membandingkan antara panjang mulut ikan dan lebar bukaan mulut ikan layur dengan ukuran umpan dan setengah tinggi mata pencing no 8, 9, dan 10 seperti terlihat pada Tabel 2. 
Tabel 2 Panjang total, panjang mulut dan lebar bukaan mulut ikan layur selama penelitian

\begin{tabular}{|c|c|c|c|c|c|c|c|c|c|c|}
\hline \multirow{3}{*}{ Bulan } & \multirow{3}{*}{$\begin{array}{c}\text { Panjang } \\
\text { total } \\
\text { layur } \\
(\mathrm{cm})\end{array}$} & \multirow{3}{*}{$\begin{array}{c}\text { Panjang } \\
\text { mulut } \\
\text { layur } \\
(\mathrm{cm})\end{array}$} & \multirow{2}{*}{\multicolumn{3}{|c|}{$\begin{array}{l}\text { Setengah tinggi } \\
\text { mata pancing dan } \\
\text { ukuran tinggi } \\
\text { umpan }\end{array}$}} & \multirow{3}{*}{$\begin{array}{c}\text { Lebar } \\
\text { bukaan } \\
\text { mulut } \\
\text { layur } \\
(\mathrm{cm})\end{array}$} & \multicolumn{3}{|c|}{$\begin{array}{l}\text { Lebar mata } \\
\text { pancing }\end{array}$} & \multirow{3}{*}{$\begin{array}{c}\text { Kondisi ikan } \\
\text { layur } \\
\text { (Tertangkap) }\end{array}$} \\
\hline & & & & & & & \multicolumn{3}{|c|}{ No mata pancing } & \\
\hline & & & $\begin{array}{l}\text { No } 8 \\
\text { (cm) }\end{array}$ & $\begin{array}{l}\text { No } 9 \\
\text { (cm) }\end{array}$ & $\begin{array}{c}\text { No } \\
10 \\
(\mathrm{~cm}) \\
\end{array}$ & & $\begin{array}{l}\text { No } 8 \\
\text { (cm) }\end{array}$ & $\begin{array}{l}\text { No } 9 \\
(\mathrm{~cm})\end{array}$ & $\begin{array}{c}\text { No } \\
10 \\
(\mathrm{~cm}) \\
\end{array}$ & \\
\hline \multirow[t]{22}{*}{ Februari } & 107 & 7,0 & 4,0 & 4,25 & 4,5 & 5,5 & 1,3 & 1,4 & 1,7 & $\sqrt{ }$ \\
\hline & 83 & 5,7 & 4,0 & 4,25 & 4,5 & 3,0 & 1,3 & 1,4 & 1,7 & $\sqrt{ }$ \\
\hline & 67 & 4,5 & 4,0 & 4,25 & 4,5 & 2,0 & 1,3 & 1,4 & 1,7 & $\sqrt{ }$ \\
\hline & 109 & 7,2 & 4,0 & 4,25 & 4,5 & 4,8 & 1,3 & 1,4 & 1,7 & $\sqrt{ }$ \\
\hline & 90 & 5,9 & 4,0 & 4,25 & 4,5 & 3,3 & 1,3 & 1,4 & 1,7 & $\sqrt{ }$ \\
\hline & 103 & 6,9 & 4,0 & 4,25 & 4,5 & 4,3 & 1,3 & 1,4 & 1,7 & $\sqrt{ }$ \\
\hline & 76 & 5,0 & 4,0 & 4,25 & 4,5 & 2,8 & 1,3 & 1,4 & 1,7 & $\sqrt{ }$ \\
\hline & 99 & 5,6 & 4,0 & 4,25 & 4,5 & 3,0 & 1,3 & 1,4 & 1,7 & $\sqrt{ }$ \\
\hline & 105 & 7,1 & 4,0 & 4,25 & 4,5 & 5,3 & 1,3 & 1,4 & 1,7 & $\sqrt{ }$ \\
\hline & 68 & 4,6 & 4,0 & 4,25 & 4,5 & 2,0 & 1,3 & 1,4 & 1,7 & $\sqrt{ }$ \\
\hline & 108 & 7,0 & 4,0 & 4,25 & 4,5 & 5,5 & 1,3 & 1,4 & 1,7 & $\sqrt{ }$ \\
\hline & 100 & 6,8 & 4,0 & 4,25 & 4,5 & 4,5 & 1,3 & 1,4 & 1,7 & $\sqrt{ }$ \\
\hline & 98 & 6,6 & 4,0 & 4,25 & 4,5 & 4,3 & 1,3 & 1,4 & 1,7 & $\sqrt{ }$ \\
\hline & 99 & 6,6 & 4,0 & 4,25 & 4,5 & 4,3 & 1,3 & 1,4 & 1,7 & $\sqrt{ }$ \\
\hline & 103 & 7,0 & 4,0 & 4,25 & 4,5 & 5,4 & 1,3 & 1,4 & 1,7 & $\sqrt{ }$ \\
\hline & 119 & 7,3 & 4,0 & 4,25 & 4,5 & 5,6 & 1,3 & 1,4 & 1,7 & $\sqrt{ }$ \\
\hline & 104 & 7,1 & 4,0 & 4,25 & 4,5 & 5,0 & 1,3 & 1,4 & 1,7 & $\sqrt{ }$ \\
\hline & 106 & 7,4 & 4,0 & 4,25 & 4,5 & 5,5 & 1,3 & 1,4 & 1,7 & $\sqrt{ }$ \\
\hline & 98 & 6,6 & 4,0 & 4,25 & 4,5 & 4,4 & 1,3 & 1,4 & 1,7 & $\sqrt{ }$ \\
\hline & 87 & 6,0 & 4,0 & 4,25 & 4,5 & 4,0 & 1,3 & 1,4 & 1,7 & $\sqrt{ }$ \\
\hline & 67 & 5,0 & 4,0 & 4,25 & 4,5 & 3,0 & 1,3 & 1,4 & 1,7 & $\sqrt{ }$ \\
\hline & 85 & 5,9 & 4,0 & 4,25 & 4,5 & 3,5 & 1,3 & 1,4 & 1,7 & $\sqrt{ }$ \\
\hline \multirow[t]{15}{*}{ Maret } & 99 & 5,8 & 4,0 & 4,25 & 4,5 & 3,4 & 1,3 & 1,4 & 1,7 & $\sqrt{ }$ \\
\hline & 79 & 5,7 & 4,0 & 4,25 & 4,5 & 3,0 & 1,3 & 1,4 & 1,7 & $\sqrt{ }$ \\
\hline & 135 & 7,5 & 4,0 & 4,25 & 4,5 & 5,5 & 1,3 & 1,4 & 1,7 & $\sqrt{ }$ \\
\hline & 102 & 7,0 & 4,0 & 4,25 & 4,5 & 5,0 & 1,3 & 1,4 & 1,7 & $\sqrt{ }$ \\
\hline & 125 & 7,2 & 4,0 & 4,25 & 4,5 & 5,5 & 1,3 & 1,4 & 1,7 & $\sqrt{ }$ \\
\hline & 145 & 7,7 & 4,0 & 4,25 & 4,5 & 5,8 & 1,3 & 1,4 & 1,7 & $\sqrt{ }$ \\
\hline & 78 & 5,6 & 4,0 & 4,25 & 4,5 & 3,2 & 1,3 & 1,4 & 1,7 & $\sqrt{ }$ \\
\hline & 98 & 5,8 & 4,0 & 4,25 & 4,5 & 3,5 & 1,3 & 1,4 & 1,7 & $\sqrt{ }$ \\
\hline & 134 & 7,3 & 4,0 & 4,25 & 4,5 & 5,6 & 1,3 & 1,4 & 1,7 & $\sqrt{ }$ \\
\hline & 121 & 7,1 & 4,0 & 4,25 & 4,5 & 5,3 & 1,3 & 1,4 & 1,7 & $\sqrt{ }$ \\
\hline & 112 & 7,0 & 4,0 & 4,25 & 4,5 & 5,1 & 1,3 & 1,4 & 1,7 & $\sqrt{ }$ \\
\hline & 100 & 6,8 & 4,0 & 4,25 & 4,5 & 4,5 & 1,3 & 1,4 & 1,7 & $\sqrt{ }$ \\
\hline & 87 & 5,8 & 4,0 & 4,25 & 4,5 & 3,5 & 1,3 & 1,4 & 1,7 & $\sqrt{ }$ \\
\hline & 77 & 5,5 & 4,0 & 4,25 & 4,5 & 3,5 & 1,3 & 1,4 & 1,7 & $\sqrt{ }$ \\
\hline & 90 & 5,9 & 4,0 & 4,25 & 4,5 & 3,6 & 1,3 & 1,4 & 1,7 & $\sqrt{ }$ \\
\hline
\end{tabular}




\begin{tabular}{|c|c|c|c|c|c|c|c|c|c|c|}
\hline \multirow{3}{*}{ Bulan } & \multirow{3}{*}{$\begin{array}{c}\text { Panjang } \\
\text { total } \\
\text { layur } \\
(\mathrm{cm})\end{array}$} & \multirow{3}{*}{$\begin{array}{c}\text { Panjang } \\
\text { mulut } \\
\text { layur } \\
(\mathrm{cm})\end{array}$} & \multirow{2}{*}{\multicolumn{3}{|c|}{$\begin{array}{l}\text { Setengah tinggi } \\
\text { mata pancing dan } \\
\text { ukuran tinggi } \\
\text { umpan }\end{array}$}} & \multirow{3}{*}{$\begin{array}{c}\text { Lebar } \\
\text { bukaan } \\
\text { mulut } \\
\text { layur } \\
(\mathrm{cm})\end{array}$} & \multicolumn{3}{|c|}{$\begin{array}{l}\text { Lebar mata } \\
\text { pancing }\end{array}$} & \multirow{3}{*}{$\begin{array}{c}\text { Kondisi ikan } \\
\text { layur } \\
\text { (Tertangkap) }\end{array}$} \\
\hline & & & & & & & \multicolumn{3}{|c|}{ No mata pancing } & \\
\hline & & & $\begin{array}{l}\text { No } 8 \\
\text { (cm) }\end{array}$ & $\begin{array}{l}\text { No } 9 \\
\text { (cm) }\end{array}$ & $\begin{array}{c}\text { No } \\
10 \\
(\mathrm{~cm}) \\
\end{array}$ & & $\begin{array}{l}\text { No } 8 \\
(\mathrm{~cm})\end{array}$ & $\begin{array}{l}\text { No } 9 \\
(\mathrm{~cm})\end{array}$ & $\begin{array}{c}\text { No } \\
10 \\
(\mathrm{~cm}) \\
\end{array}$ & \\
\hline \multirow[t]{10}{*}{ April } & 66 & 5,0 & 4,0 & 4,25 & 4,5 & 3,0 & 1,3 & 1,4 & 1,7 & $\sqrt{ }$ \\
\hline & 61 & 5,5 & 4,0 & 4,25 & 4,5 & 3,5 & 1,3 & 1,4 & 1,7 & $\sqrt{ }$ \\
\hline & 57 & 4,0 & 4,0 & 4,25 & 4,5 & 2,0 & 1,3 & 1,4 & 1,7 & $\sqrt{ }$ \\
\hline & 75 & 6,0 & 4,0 & 4,25 & 4,5 & 4,0 & 1,3 & 1,4 & 1,7 & $\sqrt{ }$ \\
\hline & 47 & 3,5 & 4,0 & 4,25 & 4,5 & 3,0 & 1,3 & 1,4 & 1,7 & $\sqrt{ }$ \\
\hline & 78 & 6,0 & 4,0 & 4,25 & 4,5 & 3,5 & 1,3 & 1,4 & 1,7 & $\sqrt{ }$ \\
\hline & 47 & 4,0 & 4,0 & 4,25 & 4,5 & 3,0 & 1,3 & 1,4 & 1,7 & $\sqrt{ }$ \\
\hline & 71 & 6,0 & 4,0 & 4,25 & 4,5 & 5,0 & 1,3 & 1,4 & 1,7 & $\sqrt{ }$ \\
\hline & 92 & 7,0 & 4,0 & 4,25 & 4,5 & 5,0 & 1,3 & 1,4 & 1,7 & $\sqrt{ }$ \\
\hline & 75 & 6,0 & 4,0 & 4,25 & 4,5 & 5,0 & 1,3 & 1,4 & 1,7 & $\sqrt{ }$ \\
\hline
\end{tabular}

Panjang total ikan layur sangat berkaitan dengan panjang mulut ikan layur. Adanya hubungan diantara keduanya dapat dilihat pada Gambar 11.

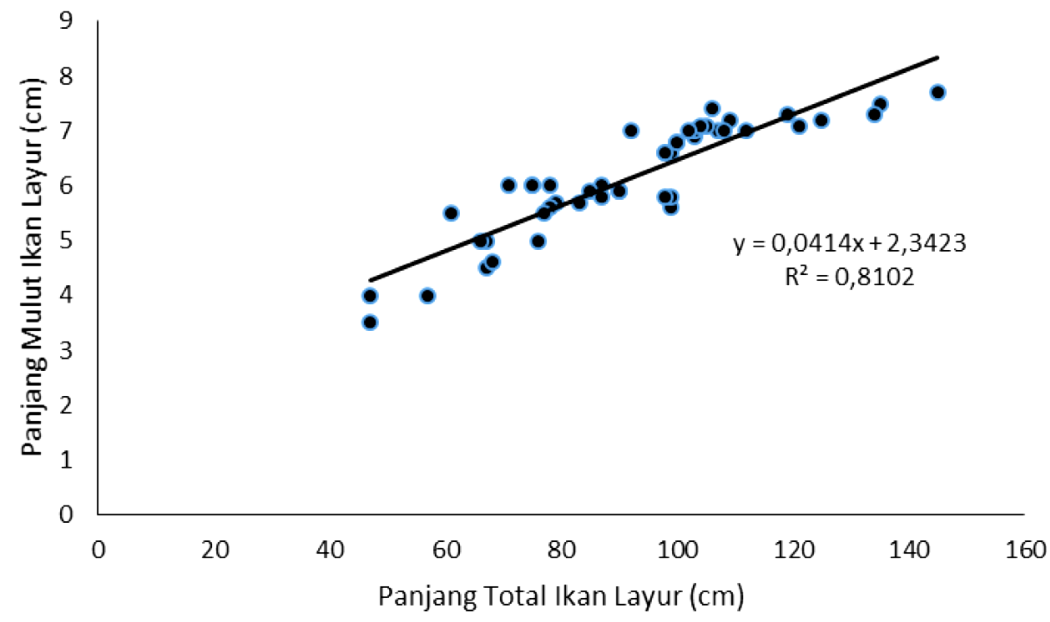

Gambar 11 Hubungan panjang total dengan panjang mulut ikan layur

Berdasarkan Gambar 11 didapatkan nilai $\mathrm{Y}=0,0414 \mathrm{x}+2,3423$ dan $\mathrm{R}^{2}=0,8102$ yang artinya hubungan panjang mulut ikan dengan panjang total ikan layur saling berkaitan, dikarenakan semakin panjang ikan layur maka akan semakin panjang pula mulut ikan layur. Hal ini dapat membantu nelayan dalam memilih ukuran mata pancing yang akan digunakan nelayan agar mendapatkan ukuran ikan layur yang diinginkan. Seperti pada Gambar 11, hubungan panjang mulut ikan layur (PM) dengan X dapat dijadikan acuan dalam menentukan panjang mata pancing yang digunakan untuk memperoleh ukuran ikan layur yang optimal. Sehingga, dapat membantu nelayan dalam memilih mata pancing yang akan digunakan pada alat tangkap pancing ulur. Panjang total ikan layur sangat berkaitan dengan lebar bukaan mulut ikan layur. Adanya hubungan diantara keduanya dapat dilihat pada Gambar 12. 


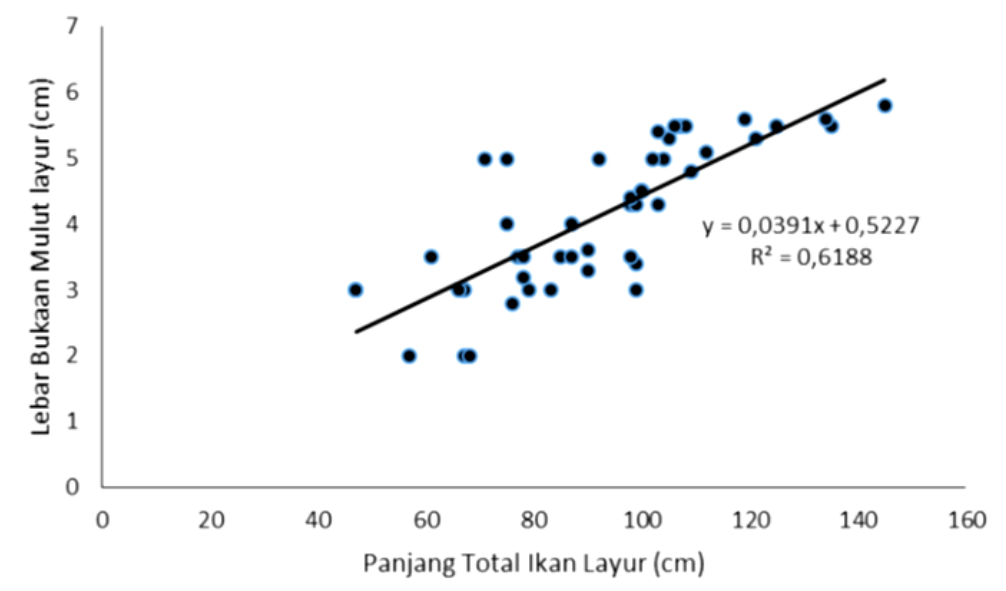

Gambar 12 Hubungan panjang total dengan lebar bukaan mulut layur

Berdasarkan gambar di atas didapatkan nilai $Y=0,0391 x+0,5227$ dan $R^{2}=0,6188$ yang artinya hubungan lebar bukaan mulut ikan dengan panjang total ikan layur saling berkaitan, dikarenakan semakin panjang ikan layur maka akan semakin lebar pula mulut ikan layur. Hal ini dapat membantu nelayan dalam memilih ukuran mata pancing yang akan digunakan nelayan agar mendapatkan ukuran ikan layur yang diinginkan. Seperti pada Gambar 12, hubungan lebar bukaan mulut ikan layur (LM) dengan $\mathrm{Y}$ dapat dijadikan acuan dalam menentukan lebar mata pancing yang digunakan untuk memperoleh ukuran ikan layur yang optimal. Sehingga, dapat membantu nelayan dalam memilih mata pancing yang akan digunakan pada alat tangkap pancing ulur.

\section{KESIMPULAN DAN SARAN}

1. Musim penangkapan ikan layur dengan jumlah banyak atau musim puncak terjadi pada musim barat (Desember, Februari, Maret) dan Musim Peralihan (April, Oktober, dan November).

2. Pola pertumbuhan ikan layur bersifat alometrik negatif yang berarti pertumbuhan panjang ikan layur lebih cepat dari pada pertumbuhan beratnya.

3. Semakin tinggi effort kecenderungan nilai CPUE semakin tinggi. Namun demikian, kecenderungan nilai CPUE pertahun semakin menurun.

4. Ukuran umpan, lebar mata pancing dan setengah tinggi mata pancing untuk mata pancing no 8, 9, dan 10 masih dalam cakupan ukuran lebar bukaan mulut dan panjang mulut ikan layur, sehingga ikan layur dapat tertangkap.

\section{DAFTAR PUSTAKA}

Anita. 2003. Pengendalian Mutu Produksi Layur (Trichiurus sp.) di Pelabuhan Perikanan Nusantara Pelabuhanratu untuk Tujuan Ekspor [skripsi]. Bogor (ID): Institut Pertanian Bogor.

Badrudin dan Wudianto. 2004. Biologi, Habitat dan Penyebaran Ikan Layur. Perikanan. [Internet]. [diunduh 2016 Feb 10]. Tersedia pada : http://www.cofish.net/ uploded/report.pdf.

Dajan A. 1998. Pengantar Metode Statistik Jilid 1. Jakarta (ID): Lembaga Penelitian Pendidikan Penerangan Ekonomi Sosial.

Dinas Kelautan dan Perikanan Sukabumi. 2013. Analisis Potensi Usaha Kelautan dan Perikanan. Sukabumi (ID): Dinas Kelautan dan Perikanan Kabupaten Sukabumi.

Effendie MI. 1979. Metoda Biologi Perikanan. Bogor (ID): Yayasan Dewi Sri.

Fauzi A, Anna S. 2005. Per modelan Sumberdaya Perikanan dan Kelautan (untuk Analisis Kebijakan). Jakarta (ID): PT. Gramedia Pustaka Utama. 
Gulland JA. 1983. Fish Stok Assesment: A Manual of Basic Methods. Chichester- New York - Brisbane - Toronto - Singapore : John Willey and Sons.

Harjanti R, Pramonowibowo, Hapsari TD. 2012. Analisis Musim Penangkapan dan Tingkat Pemanfaatan Ikan Layur (Trichiurus sp) di Perairan Palabuhanratu, Sukabumi, Jawa Barat. Journal of Fisheries Resources Utilization Management and Technology.1(1):55-66

Sari FW. 2008. Studi Kebiasaan Makanan Ikan Layur (Superfamili Trichiuroidea) Di Perairan Palabuhanratu [Skripsi]. Semarang (ID): Universitas Diponegoro.

Vianita R. 2014. Aspek Biologi Layur (Trichiurus lepturus) Berdasarkan Hasil Tangkapan di PPP Morodemak. Diponegoro Journal of Maquares. 3(3):160-167

Walpole RE. 1995. Pengantar Statistika. Sumantri B, penerjemah. PT. Gramedia Pustaka Utama. Jakarta (ID): Terjemahan dari : Introduction to Statistic. $515 \mathrm{hlm}$.

Widyanto IN. 2008. Kajian Pola Pertumbuhan dan Ciri Morfometrik-Meristik Beberapa Species Ikan Layur (Superfamili Trichiuroidea) di Perairan Palabuhanratu, Sukabumi, Jawa Barat [Skripsi]. Bogor (ID): Institut Pertanian Bogor.

\section{LAMPIRAN}

Dokumentasi penelitian

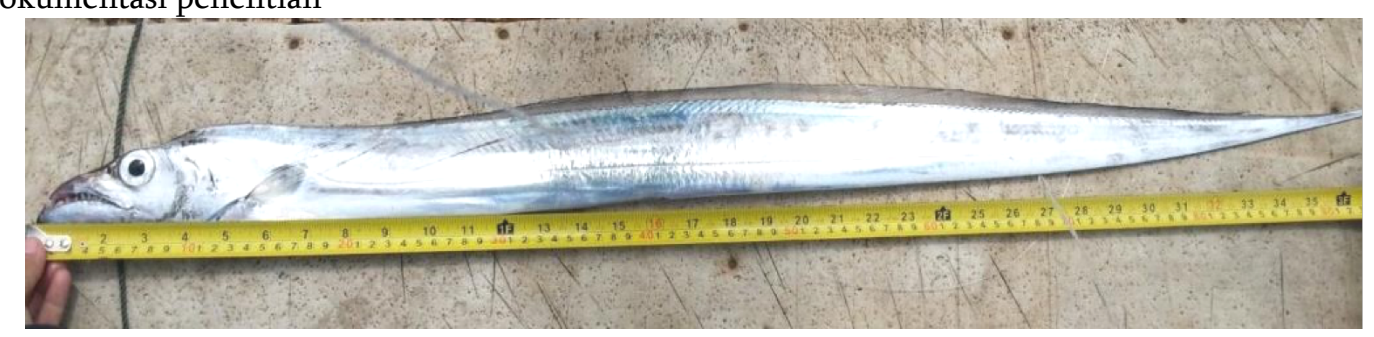

Ukuran panjang total layur

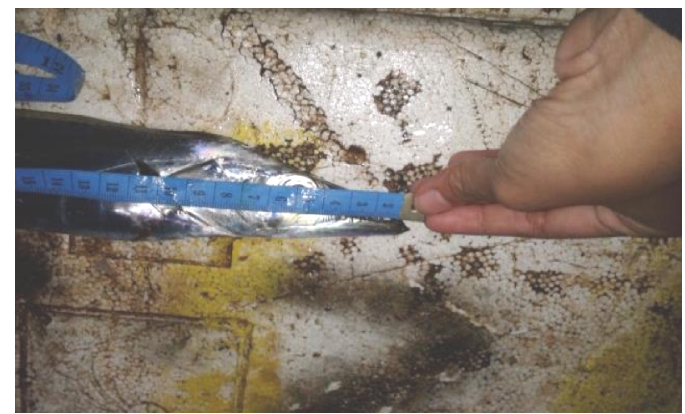

Ukuran panjang mulut layur

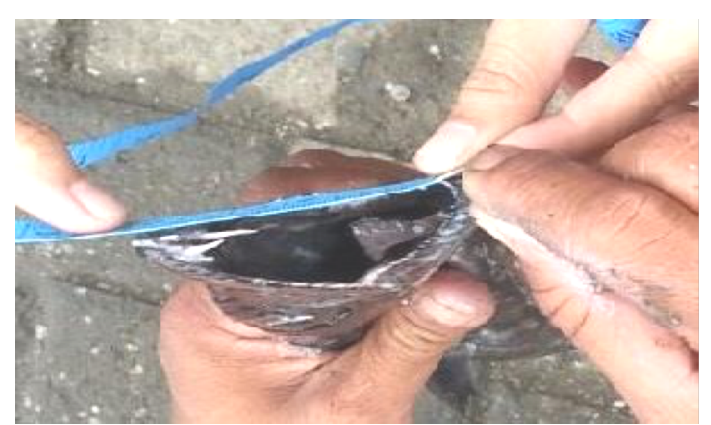

Ukuran lebar bukaan mulut layur 


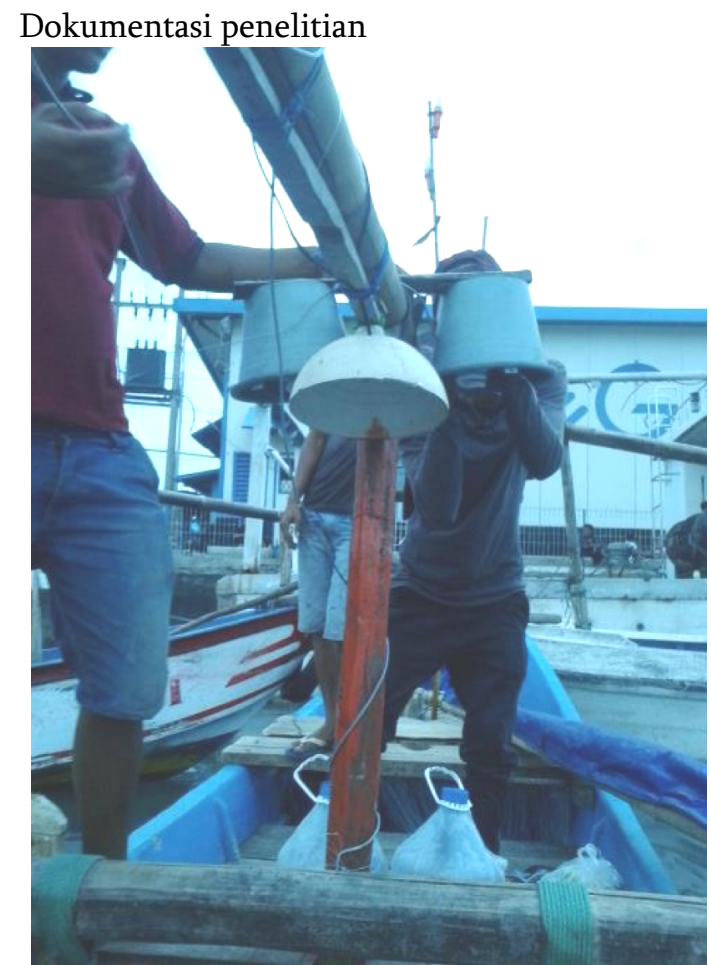

Persiapan ketika melaut

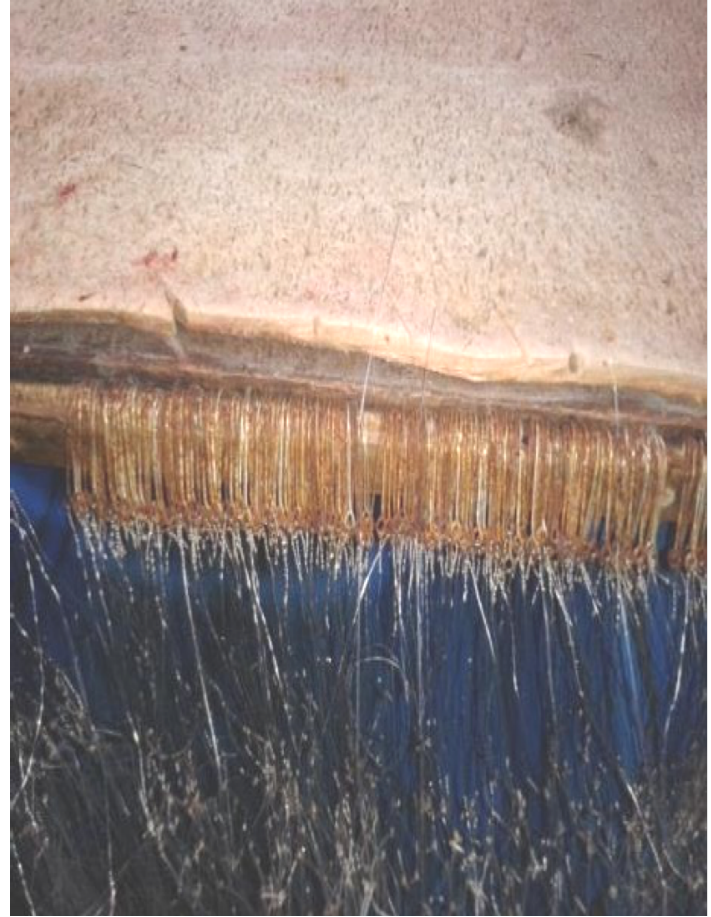

Mata pancing layur 